\title{
Implied Equity Duration: A New Measure of Equity Risk
}

\author{
PATRICIA M. DECHOW \\ dechow@umich.edu \\ University of Michigan Business School, Ann Arbor, MI 48109 \\ RICHARD G. SLOAN* \\ University of Michigan Business School, 701 Tappan Street, Ann Arbor, MI 48109-1234
}

MARK T. SOLIMAN

Soliman_Mark@GSB.Stanford.edu

Stanford Graduate School of Business, Stanford, CA 94305

\begin{abstract}
Duration is an important and well-established risk characteristic for fixed income securities. We use recent developments in financial statement analysis research to construct a measure of duration for equity securities. We find that the standard empirical predictions and results for fixed income securities extend to equity securities. We show that stock price volatility and stock beta are both positively correlated with equity duration. Moreover, estimates of common shocks to expected equity returns extracted using our measure of equity duration capture a strong common factor in stock returns. Additional analysis shows that the book-to-market ratio provides a crude measure of equity duration and that our more refined measure of equity duration subsumes the Fama and French (1993) book-to-market factor in stock returns. Our research shows how structured financial statement analysis can be used to construct superior measures of equity security risk.
\end{abstract}

Keywords: duration, asset pricing, risk, financial statement analysis

JEL Classification: G12, G14, M41

Techniques for analyzing the risk characteristics of fixed income securities have evolved within a theoretically rigorous framework based on the discounted expectations of the future cash flows of the securities. Constructs such as duration and immunization are well established for fixed income securities and are embraced by academics and practitioners alike. The analysis of equity securities, in contrast, has evolved in a relatively ad hoc manner. Academics and practitioners have adopted empirically motivated procedures for the analysis of equity risk. For example, following Fama and French (1993), a popular academic approach to modeling the risk characteristics of stock returns is through a three-factor model incorporating market-related, size-related, and book-to-market-related factors. Similarly, practitioners have embraced the notion of classifying stocks on the basis of market capitalization and the extent to which they exhibit the "style" characteristics of "value" and "growth". We bridge the gap between the analysis of fixed income and equity securities by developing a measure of duration for equity securities.

*Corresponding author. 
With a few exceptions, most notably Lanstein and Sharpe (1978), equity duration has received little attention in the academic or practitioner literature. ${ }^{1} \mathrm{We}$ demonstrate that a measure of equity duration computed using financial statement data provides both a theoretically justifiable and empirically powerful technique for the analysis of equity security risk.

We begin by developing a measure of implied equity duration based on Macaulay's (1938) traditional measure of bond duration. The primary obstacle in implementing the bond duration formula for equities is in the estimation of the expected future cash distributions. We develop a two-stage procedure to facilitate this task. First, we use information in the financial statements to generate forecasts of expected future cash flows over a finite forecast horizon. Second, we assume that the remaining value implicit in the observed stock price will be distributed as a level perpetuity beyond our finite forecast horizon. We then apply the standard duration formula to compute our measure of implied equity duration. We recognize that our estimation procedure for implied equity duration represents a simple approximation based on relatively crude forecasting assumptions. Nevertheless, the resulting duration estimates perform well in empirical tests, and our basic framework is easily adapted to incorporate more sophisticated forecasts.

Empirical tests demonstrate the effectiveness of our measure of implied equity duration in explaining the risk characteristics of equity security returns. Implied equity duration is strongly positively correlated with stock return volatilities and betas and has incremental explanatory power over past volatilities/betas in forecasting future volatilities/betas. Moreover, estimates of common shocks to expected equity returns extracted using our measure of implied equity duration capture a strong common factor in stock returns. We also show that the book-tomarket ratio represents a special case of our expression for implied equity duration that imposes restrictive assumptions on the evolution of future cash flows. Consequently, our implied equity duration framework provides a rigorous explanation for the empirical properties of the book-to-market-related factor documented in Fama and French (1993). Empirical tests confirm that the common factor related to our measure of implied equity duration subsumes the common factor related to book-to-market.

Finally, we use our measure of implied equity duration to estimate an equity yield curve. Our results indicate that long-duration equities have historically generated lower average returns, suggesting that equity investors have long investment horizons and require a premium to hold short-duration equities. These findings are consistent with recent research by Campbell and Vuolteenaho (2003) and Brennan and Xia (2003) on the pricing of beta risk. Long-duration equities tend to be "growth" stocks that have higher betas due to their greater sensitivity to expected return shocks. But because equity investors have long investment horizons, they do not appear to require a premium to hold beta risk arising from expected return shocks. However, an alternative interpretation of these findings, consistent with Lakonishok et al. (1994) and Daniel et al. (1998, 2001), is that investors are irrationally optimistic about the future prospects of long duration stocks. Long duration stocks tend to have market valuations that are high relative to their current 
fundamentals. Hence, they may be "glamour" stock and their low future stock returns may reflect investor disappointment as they fail to live up to investors' high expectations.

\section{Implied Equity Duration: Definition, Measurement and Predictions}

\subsection{Definition and Measurement}

The traditional measure of duration $(D)$ for a bond is the Macaulay duration formula:

$$
D=\frac{\sum_{t=1}^{T} t \times\left(C F_{t} /(1+r)^{t}\right)}{P},
$$

where $C F$ denotes the cash flow at time $t, r$ denotes the yield to maturity and $P$ denotes the bond price. This measure of duration is a weighted average of the time to the receipt of each of the respective cash flows on the bond, where the weights represent the relative contributions of the cash flows to the bond's value. Intuitively, duration represents the average maturity of the bond's promised cash flows.

The primary role of duration in the analysis of fixed income securities is as a measure of bond price sensitivity to changes in the yield to maturity. Differentiating the expression for the value of a bond with respect to the yield to maturity gives:

$$
\frac{\partial P}{\partial r}=-P \times \frac{D}{1+r} .
$$

Intuitively, this result indicates that the relation between bond prices changes and changes in bond yields is a simple function of duration: ${ }^{2}$

$$
\frac{\Delta P}{P} \approx-\frac{D}{1+r} \Delta r
$$

The expression $D /(1+r)$ is often referred to as the "modified duration," and it provides a simple measure of the sensitivity of bond prices changes to yield changes. Extending the duration concept to equities introduces two key problems:

1. A bond typically makes a finite number of cash payments, while the sequence of payments on equity securities is potentially infinite.

2. The amount and timing of the cash payments on a bond are usually specified in advance and subject to little uncertainty, while the payments on equity securities are not specified in advance and can be subject to great uncertainty.

To address the first problem, we partition the duration formula in equation (1) into two parts, a finite forecasting horizon of length $T$ and an infinite terminal 
expression:

$$
\begin{aligned}
D= & \frac{\sum_{t=1}^{T} t \times C F_{t} /(1+r)^{t}}{\sum_{t=1}^{T} C F_{t} /(1+r)^{t}} \times \frac{\sum_{t=1}^{T} C F_{t} /(1+r)^{t}}{P} \\
& +\frac{\sum_{t=T+1}^{\infty} t \times C F_{t} /(1+r)^{t}}{\sum_{t=T+1}^{\infty} C F_{t} /(1+r)^{t}} \times \frac{\sum_{t=T+1}^{\infty} C F_{t} /(1+r)^{t}}{P} .
\end{aligned}
$$

Since we are now dealing with equity, $P$ denotes the market capitalization of equity (stock price multiplied by shares outstanding), $C F$ denotes the net cash distributions to equity holders and $r$ denotes the expected return on equity. Equation (4) expresses equity duration as the value-weighted sum of the duration of the finite forecasting horizon cash flows and the duration of the infinite terminal cash flows. Next, we assume that the terminal cash flow stream consists of a level perpetuity with a value equal to the difference between the observed market capitalization implicit in the stock price and the present value of the cash flows over the finite forecast period, so that:

$$
\sum_{t=T+1}^{\infty} \frac{C F_{t}}{(1+r)^{t}}=\left(P-\sum_{t=1}^{T} \frac{C F_{t}}{(1+r)^{t}}\right)
$$

Recognizing that the duration of a level perpetuity beginning in $T$ periods is $T+(1+r) / r$, and substituting (5) into (4) simplifies our expression for equity duration to:

$$
D=\frac{\sum_{t=1}^{T} t \times C F_{t} /(1+r)^{t}}{P}+\left(T+\frac{1+r}{r}\right) \times \frac{\left(P-\sum_{t=1}^{T} C F_{t} /(1+r)^{t}\right)}{P} .
$$

The assumption that the cash flow stream for an equity security can be partitioned into a finite forecasting period and an infinite terminal expression is standard in the equity valuation literature. The assumption that the terminal cash flows are realized as a level perpetuity is less standard. More commonly, the terminal cash flows are assumed to grow at a constant terminal rate, such as the expected macroeconomic growth rate. We make the level perpetuity assumption for tractability and without loss of generality. As long as the forecasting horizon is long enough to exhaust plausible opportunities for firm-specific or industry-specific super-normal growth, the terminal growth rate will be a cross-sectional constant, and so will not be an important source of cross-sectional variation in implied equity duration. Because the terminal cash flow perpetuity is inferred from the observed stock price, we refer to the resulting measure of equity duration as "implied" equity duration. In other words, our measure of equity duration is based on investors' consensus expectations, as reflected in stock prices, rather than on necessarily rational forecasts of future cash flows.

The discussion above deals with the infinite cash flow problem. The second problem in implementing equation (6) is the forecasting of the finite period cash 
distributions, $C F_{t}, 0<t \leq T$. Our forecasting model is based on recent research indicating that accounting-based performance measures provide effective information variables for forecasting future cash flows (Nissim and Penman, 2001). We begin with the accounting identity that expresses net cash distributions to equity in terms of earnings and book value of equity: ${ }^{3}$

$$
C F_{t}=E_{t}-\left(B V_{t}-B V_{t-1}\right),
$$

where $E_{t}$ represents accounting earnings at the end of period $t$ and $B V_{t}$ represents the book value of equity at the end of period $t$. Re-arranging the right-hand side of equation (7) gives:

$$
C F_{t}=B V_{t-1} \times\left[\frac{E_{t}}{B V_{t-1}}-\frac{\left(B V_{t}-B V_{t-1}\right)}{B V_{t-1}}\right]
$$

Equation (8) indicates that to forecast net cash distributions to equity, one needs to first forecast:

i. Return on equity (ROE) denoted by $E_{t} / B V_{t-1}$; and

ii. Growth in equity, denoted by $\left(B V_{t}-B V_{t-1}\right) / B V_{t-1}$.

It is well established that ROE follows a slowly mean reverting process (Stigler, 1963; Penman, 1991). Moreover, both economic intuition and empirical evidence suggest that the mean to which ROE reverts approximates the cost of equity (Nissim and Penman, 2001). We therefore model ROE as a first-order autoregressive process with an autocorrelation coefficient based on the long-run average rate of mean reversion in ROE and a long-run mean equal to the cost of equity.

To forecast growth in equity, we rely on the results in Nissim and Penman (2001) indicating that past sales growth is a better indicator of future equity growth than past equity growth. Sales growth follows a mean reverting process similar to ROE, but mean reversion in sales growth tends to be more rapid (see Nissim and Penman, 2001). Economic intuition suggests that the mean to which sales growth reverts should approximate the long-run macroeconomic growth rate. ${ }^{4}$ We therefore model growth in equity as a first-order autoregressive process, with an autocorrelation coefficient equal to the long-run average rate of mean reversion in sales growth and a mean equal to the long-run GDP growth rate.

Note that the forecast of the growth in equity embodies not only a forecast of future growth in a firm's operating activities (as reflected in sales growth), but also a forecast of its future capital structure. A firm could grow its equity without growing its sales by using free cash flow to either pay down debt or accumulate financial assets. Under such circumstances, a firm could potentially engage in financing transactions that would alter the duration of its equity. In other words, the duration of a firm's equity securities is determined by both the duration of the cash flows generated by its investment opportunity set and by its financing policy. A firm whose free cash flows have a short duration could invest these cash flows in 30-year bonds, 
thus increasing the duration of the firm's equity securities. By assuming that book value grows in line with sales growth, we are implicitly assuming that the firm's capital structure remains constant. This assumption is supported by the results in Nissim and Penman (2001), who find that capital structure is relatively persistent. ${ }^{5}$

Implementation of our estimation procedure for implied equity duration requires four financial variables and four forecasting parameters as inputs. We summarize these inputs in Table 1. The four financial variables are book value (both current and lagged one year), sales (both current and lagged one year), earnings (current) and market capitalization (current). The four forecasting parameters are the autocorrelation coefficient for ROE, the autocorrelation coefficient for sales growth, the expected return on equity and the long-run GDP growth rate. We conduct our analysis using annual data and obtain the required financial variables from the annual COMPUSTAT files. Using pooled data over our sample period, we obtain average estimates of the autocorrelation coefficients for ROE and sales growth of 0.57 and 0.24 , respectively.

Estimates of return on equity and GDP growth rate are based on the long-run averages reported by Ibbotson (1999) of (approximately) 12 and 6\%, respectively. Note that we use a naïve forecast of the expected return on equity, assuming it to be a cross-sectional constant. It is possible that the expected return varies systematically with duration. For example, long duration "growth" stocks could have higher expected returns than short duration stocks. Higher discount rates generally lead to lower duration calculations (because more distant cash flows receive lower weights). It is implausible, however, that expected return differences could be large enough to reverse the rank ordering of firms based on duration. ${ }^{6}$ Furthermore, it is well

Table 1. Summary of financial variables and forecasting parameters used in the estimation of implied equity duration.

\begin{tabular}{ll}
\hline $\begin{array}{l}\text { Panel A: Financial Variables } \\
\text { Financial Variable }\end{array}$ & Compustat Definition \\
\hline $\begin{array}{l}\text { Book value of equity }(B V) \\
\text { Earnings }(E)\end{array}$ & $\left.\begin{array}{l}\text { Data Item } 60 \\
\text { Data Item } 18=\text { Income before extraordinary items } \\
\text { Data Item } 12\end{array}\right)$ \\
$\begin{array}{l}\text { Market capitalization } \\
\text { Data Item } 199 \times \text { Data Item } 25\end{array}$ \\
$\begin{array}{l}\text { Panel B: Forecasting Parameters } \\
\text { Forecasting Parameter }\end{array}$ & Value \\
\hline Autocorrelation coefficient for return on equity & 0.57 \\
Cost of equity capital & 0.12 \\
Autocorrelation coefficient for growth in & 0.24 \\
$\quad$ sales/book value & \\
Long-run growth rate in sales/book value & 0.06 \\
\hline
\end{tabular}

The autocorrelation coefficients are based on pooled autoregressions for return on equity and sales growth using a sample of 139,404 observations over compustat years 1950 to 1999. The cost of equity capital and long-run growth rates are based on their long-run historical averages. 
established that long-duration "growth" stocks firms tend to have lower average future returns than short-duration "value" stocks, suggesting that long-duration firms actually have lower expected returns. Thus, if anything, our constant cost of capital assumption is more likely to understate cross-sectional differences in duration. By assuming that the expected return is a cross-sectional constant, we also ensure that our measure of implied equity duration is driven solely by differences in the timing of the expected future cash flows. We avoid the criticism that our empirical results are simply an artifact of the way in which we measure the expected return. ${ }^{7}$

Finally, we use a finite forecast horizon of ten years, because most of the mean reversion in sales growth and ROE is complete after ten years. We emphasize that all of the aforementioned forecasting procedures are relatively crude. For example, most of our forecasting parameters are likely to vary as a function of industry membership and other firm characteristics. However, our immediate goal is to introduce the concept of implied equity duration and demonstrate the ability of a relatively parsimonious empirical estimation procedure to produce an effective measure of implied equity duration.

\subsection{Examples Illustrating Our Implied Equity Duration Measurement Procedure}

Table 2 illustrates our implied equity duration measurement procedure using two representative firm-year observations from our sample. The first example in panel A is for Alaska Air in 1999 and is illustrative of low duration equity. The second example in panel B is for Amazon.com in 1999 and is illustrative of high duration equity. Values for the required forecasting variables are listed at the top left of each panel and the forecasting parameters, which are assumed to be the same across firms, are listed at the top right. Forecasts of cash flows and their present values are derived for the ten-year forecast horizon. The growth rate is derived by reverting past sales growth to the long-run mean of $6 \%$ using the autocorrelation coefficient of 0.24 . Similarly, ROE is derived by reverting past ROE to its long run mean of $12 \%$ using the autocorrelation coefficient of 0.57 . Applying the forecast growth rates to lagged book value generates the forecasts of future book values. Applying the forecast ROEs to the lagged book value forecasts generates the earnings forecasts. Cash flow forecasts are then extracted from the earnings and book value forecasts using equation (7).

The weight assigned to the finite 10 -year duration period is equal to the ratio of the present value of the 10-year cash flows to the market capitalization. The terminal period duration is always equal to 19.33 [i.e., $T+(1+r) / r=10+1.12 / 0.12=$ 19.33]. The weight assigned to the terminal period duration is simply one minus the weight assigned to the finite period duration. Implied equity duration is the weighted sum of the finite and terminal period durations.

The computation for Alaska Air indicates that $64 \%$ of the value implicit in the current price is expected to be realized during the finite forecast period. Alaska Air's forecast ROE exceeds its forecast growth rate in every year of the finite forecast 


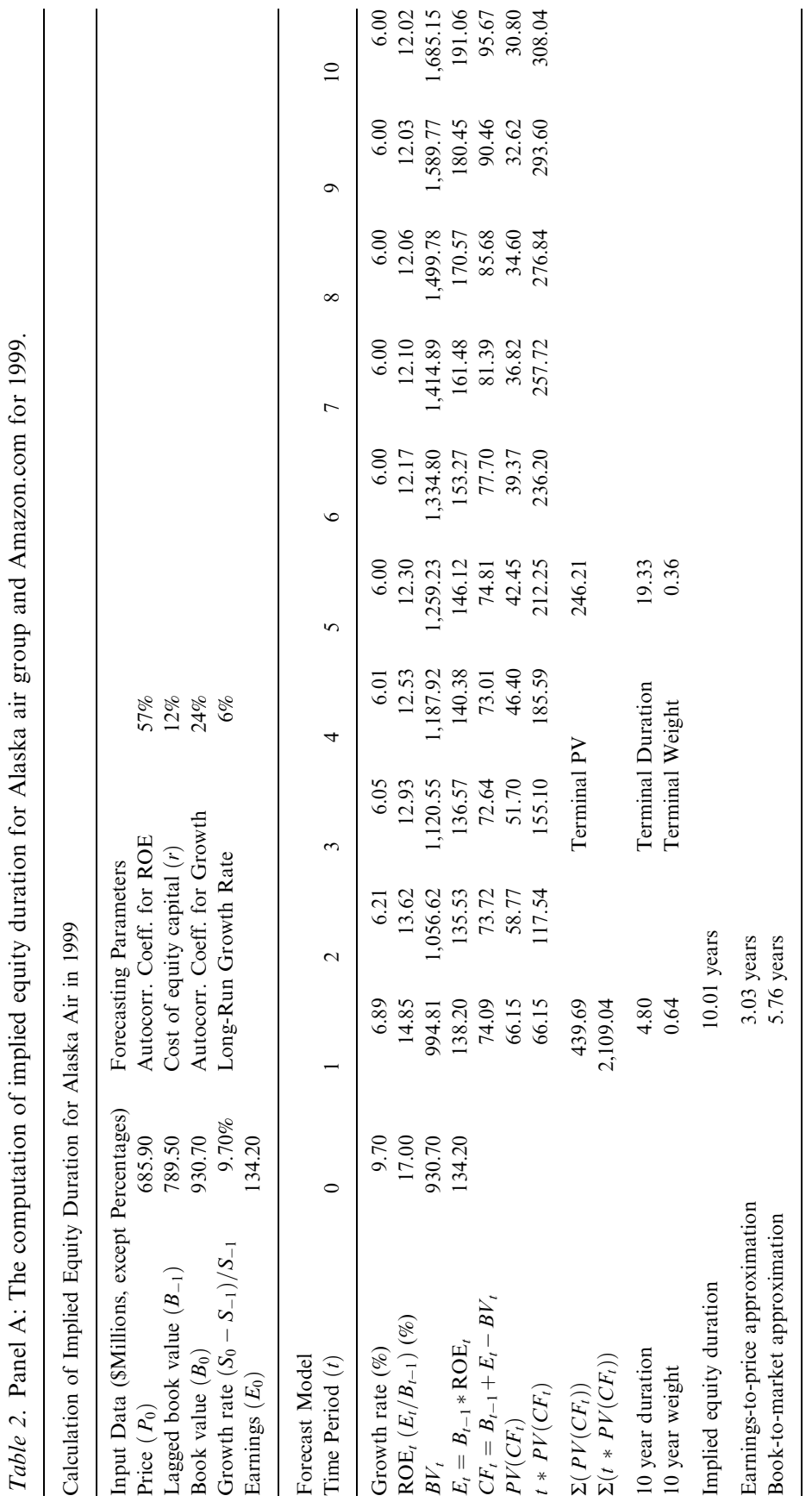




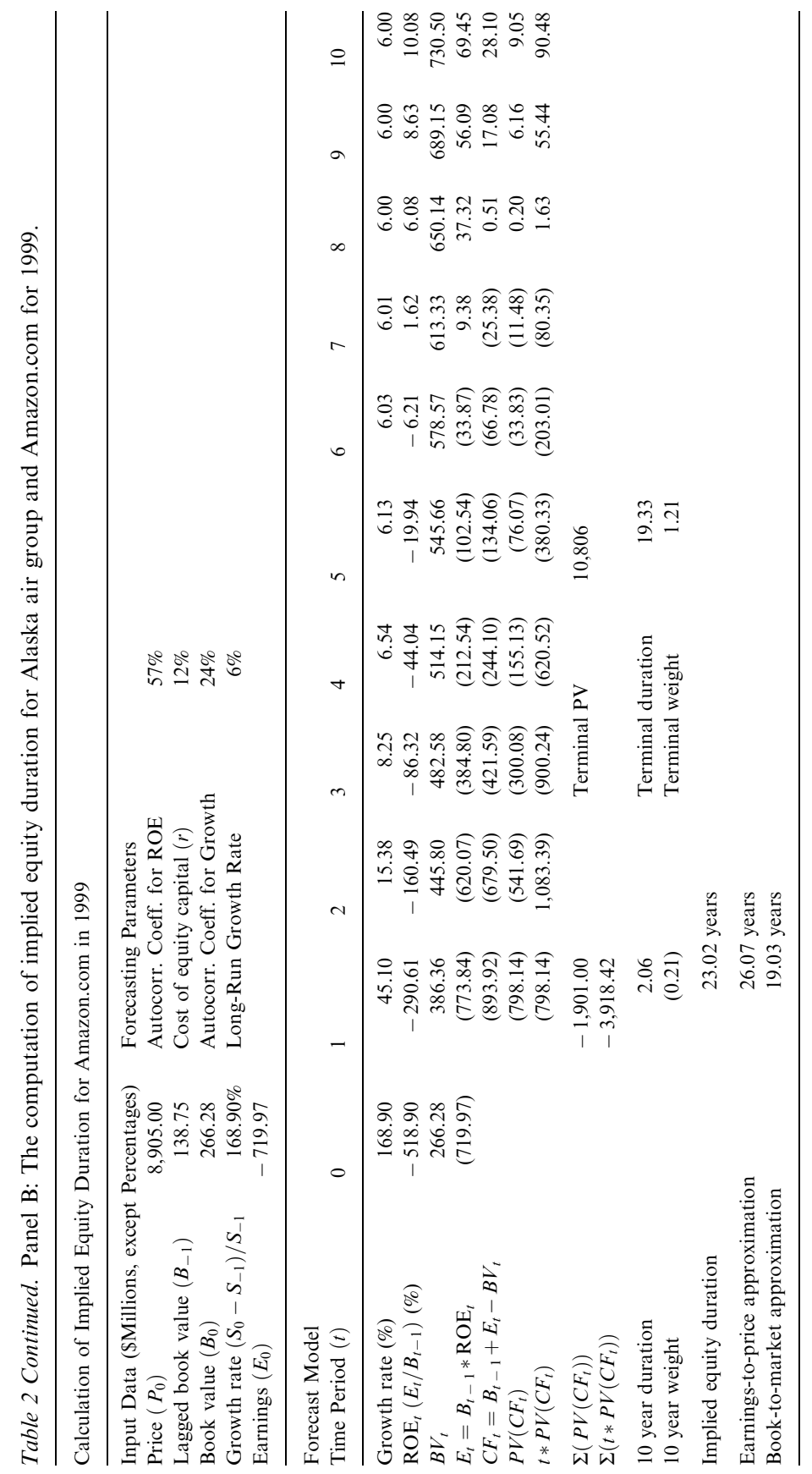


period, which results in positive cash distributions in each of these periods. This results in a relatively low implied equity duration figure of just 10.0 years for Alaska Air. The computation for Amazon.com indicates that the cash flows realized during the forecast period amount to $-21 \%$ of the value implicit in the current price. In Amazon's case, the negative current ROE and high growth rate combine to generate cash flows over the finite forecast period that are mostly negative and have a negative net present value. Implicit in this negative cash flow is the necessity for Amazon.com to raise additional capital over the finite forecasting horizon. In order for cash distributions to be positive, the ROE must exceed the growth rate in book value, and this does not happen in the Amazon example until year 8. As a consequence of the negative weighting on the finite forecast period duration, Amazon's implied equity duration of 23.0 years exceeds the terminal period duration of 19.33 years. Thus, duration tends to be high for firms with low ROE and high growth. Duration is also high for firms in which the present value of the estimated finite period cash flows represents a smaller proportion of their market capitalization.

\subsection{Equity Duration and the Earnings-to-Price and Book-to-Market Ratios}

Finance practitioners and academics frequently use earnings-to-price and book-tomarket ratios as equity style and risk characteristics. Our measure of implied equity duration is closely related to these valuation ratios. We demonstrate the links by considering some special cases of the implied equity duration formula in equation (6). These special cases all involve the assumption that the net cash distributions over the finite forecasting period take the form of a level annuity, denoted $A$. The duration of a level annuity of length $T$ is given by:

$$
D_{A}=\frac{1+r}{r}-\frac{T}{(1+r)^{T}-1},
$$

and the present value of a level annuity of amount $A$ and length $T$ is given by:

$$
P V_{A}=A \times \frac{1-\left(1 /(1+r)^{T}\right)}{r} .
$$

Substituting these two equations into equation (6) and simplifying yields:

$$
D=T+\frac{1+r}{r}-\frac{A / r}{P} \times T .
$$

This expression highlights the fact that implied equity duration is decreasing in the magnitude of the net cash distributions paid over the finite forecast horizon. Differentiating (11) with respect to $A$ gives:

$$
\frac{\partial D}{\partial A}=\frac{-T}{r \times P} .
$$


Duration is decreasing in the magnitude of the annuity, with the rate of decrease being larger for longer forecast horizons, lower discount rates and lower stock valuations.

Equation (11) is the key to understanding the relation between implied equity duration, the earnings-to-price ratio and the book-to-market ratio. Recall equation (8), which expressed the net cash distributions received over the finite forecast horizon as:

$$
C F_{t}=B V_{t-1} \times\left[\frac{E_{t}}{B V_{t-1}}-\frac{\left(B V_{t}-B V_{t-1}\right)}{B V_{t-1}}\right] .
$$

If we assume that growth in equity is zero for all finite forecast periods (i.e., $B V_{t}=$ $B V_{-1}$ for $\left.0<t \leq T\right)$ and that there will be perfect persistence of current ROE over the forecast period (i.e., $\left(E_{t} / B V_{t-1}\right)=\left(E_{0} / B V_{-1}\right)$ for $\left.0<t \leq T\right)$, then $C F_{t}=E_{0}$ for $0<t \leq T$. The amount of the annuity for the finite forecast horizon is now equal to earnings at the beginning of the forecast horizon, and equation (11) becomes:

$$
D=T+\frac{1+r}{r}-\frac{E_{0}}{P} \times \frac{T}{r} .
$$

Here, we see that there is a negative relation between implied equity duration and the earnings-to-price ratio. So the earnings-to-price ratio will be a good proxy for equity duration in firms where growth in equity is low and ROE is highly persistent. Table 2 provides estimates of implied equity duration for Alaska Air and Amazon.com based on equation (13), labeled "earnings-to-price approximation." The approximation based on (13) understates duration for Alaska Air, because Alaska Air has a high current ROE and maintaining the ROE over the finite horizon results in the higher cash distributions. On the other hand, equation (13) overstates duration for Amazon, because Amazon has a very negative ROE and maintaining the ROE over the finite forecast horizon results in more required capital infusions.

To see the relation between implied equity duration and the book-to-market ratio, assume that growth in equity is again zero over the forecast period but that ROE immediately mean reverts to the cost of capital in the first year of the forecast period (i.e., $\left(E_{t} / B V_{t-1}\right)=r$ for $0<t \leq T$ ). Equation (8) now simplifies to $C F_{t}=r \times B V_{0}$. The amount of the annuity for the finite forecast horizon is equal to book value at the beginning of the forecast horizon multiplied by the cost of capital, and implied equity duration becomes:

$$
D=T+\frac{1+r}{r}-\frac{B V_{0}}{P} \times T .
$$

In this special case, there is a simple negative relation between implied equity duration and the book-to-market ratio. The book-to-market ratio will be a good proxy for duration for firms where growth in equity is low and ROE is rapidly mean reverting. Table 2 provides estimates of implied equity duration for Alaska Air and Amazon.com based on equation (14) labeled "book-to-market approximation." The approximation based on (14) understates duration for both Alaska Air and 
Amazon.com. For Alaska Air, the understatement arises because the implicit assumption of no growth in equation (14) results in higher cash distributions in the finite forecast period. For Amazon, the understatement arises because the implicit assumptions of no growth and the immediate mean reversion to a positive ROE result in higher cash distributions in the finite forecast period.

The close links between our measure of implied equity duration and these popular valuation ratios suggest that these ratios may serve as crude proxies for equity duration. Many previous studies document empirical regularities involving these ratios. Our paper provides a framework for understanding and explaining these empirical regularities. For example, Fama and French (1995) show that firms with low book-to-market ratios have higher equity betas. Our equity duration framework suggests that the higher betas arise because stocks with low book-to-market ratios have longer durations and hence are more sensitive to expected return shocks. However, we again emphasize that even the forecasting procedures that we use to measure implied equity duration measure are relatively crude. Consequently, both valuation ratios and measures of implied equity duration using more refined inputs, such as analysts' earnings forecasts, should yield further improvements.

\subsection{Empirical Predictions}

The primary empirical implication of duration stems from the relation between ex post holding period returns and changes in expected return. Denoting holding period returns as $h$ and changes in expected return as $\Delta r$, equation (3) indicates that the influence of a change in expected return on the ex post holding period is:

$$
h=\frac{\Delta P}{P} \approx-\frac{D}{1+r} \Delta r .
$$

Empirical verification of the relation in (15) is difficult, because changes in expected equity returns are not directly observable. Nevertheless, we can use (15) to generate predictions concerning the role played by duration in transmitting expected return volatility to holding period return volatility. First, defining volatility in terms of the standard deviation $(\sigma)$, we can use (15) to determine the impact of volatility in expected returns on the volatility of holding period returns:

$$
\sigma(h) \approx \frac{D}{1+r} \sigma(\Delta r) .
$$

Note that equation (16) only models the role of expected return shocks on volatility. It ignores other potential sources of volatility, such as cash flow shocks. Equation (16) indicates that the impact of expected return volatility on holding period return volatility is greater for long duration stocks. This leads to our first empirical prediction:

P1: The volatility of equity holding period returns is increasing in equity duration. 
Our first prediction relates to the total volatility of equity returns. However, assetpricing theory suggests that non-diversifiable volatility constitutes a more relevant measure of risk. In particular, the capital asset pricing model indicates that only systematic risk $(\beta)$ that is related to movements in the market portfolio should be priced. Defining $h_{m}$ as the ex post holding-period return on the market portfolio, $D_{m}$ as the duration of the market portfolio and $r_{m}$ as the expected return on the market portfolio, we can use (15) to determine the impact of common shocks to expected returns, $\left(\Delta r_{m}\right)$ on systematic risk $\left(\beta\left(h, h_{m}\right)\right)$ :

$$
\beta\left(h, h_{m}\right)=\frac{\sigma\left(h, h_{m}\right)}{\sigma^{2}\left(h_{m}\right)} \approx \frac{D}{D_{m}} \times \frac{1+r_{m}}{1+r} \times \beta\left(\Delta r, \Delta r_{m}\right) .
$$

The final term in (17) represents the sensitivity of changes in the expected return on the equity security to changes in the expected return on the market portfolio. There is a large body of empirical evidence documenting strong common shocks to expected equity returns (e.g., Campbell and Shiller, 1988; Campbell and Mei, 1993). Thus, we expect the final term to be positive and close to one for the typical equity security. Equation (17) indicates that the impact of common expected return volatility on holding period return volatility is increasing in the duration of the equity security relative to the duration of the market portfolio. Equation (17) forms the basis for our second prediction:

\section{P2: Equity betas computed from holding-period returns are increasing in the duration of the equity relative to the duration of the market portfolio.}

Tests of our second prediction build on evidence in Campbell and Mei (1993) and Cornell (1999). Campbell and Mei use a log-linear approximation of returns to estimate the proportion of the variation in beta attributable to common variation in cash flows versus common variation in expected returns. They find that variation in betas is largely attributed to common innovations in expected returns. Thus, their evidence implies that equation (17) should capture an important determinant of beta. Cornell anticipates our second prediction by recognizing that Campbell and Mei's results imply that equity duration should be an important determinant of betas. $\mathrm{He}$ presents preliminary tests in this respect by correlating betas with earnings-to-price ratios, dividend-to-price ratios and growth forecasts. Cornell provides mixed and indirect evidence in support of $P 2$. We build on Cornell's results by constructing more direct tests of $P 2$.

$P 2$ rests on the assumption that some shocks to expected returns are common across securities; however, it does not necessarily rule out the case of idiosyncratic shocks. For example, liquidity has been proposed as an important determinant of expected returns (e.g., Amihud and Mendelson, 1983). Therefore, events having an impact on a firm's liquidity, such as changes in exchange listing, addition/removal from an index and the listing of derivative securities, may result in idiosyncratic shocks to expected returns. Denoting $h_{f}$ and $r_{f}$ as the firm-specific components of 
realized and expected returns respectively and substituting into (16) yields:

$$
\sigma\left(h_{f}\right) \approx \frac{D}{1+r} \sigma\left(\Delta r_{f}\right)
$$

from which we generate our third prediction:

P3: The standard deviation of the idiosyncratic component of realized holding-period returns is increasing in equity duration.

Our first three predictions concern associations between equity duration and common measures of volatility. Our remaining predictions concern the ability of equity duration to capture a unique common factor in stock returns. We estimate a factor related to duration using two alternative procedures. Our first procedure uses a straightforward regression approach that attempts to directly estimate the common shocks to expected returns through cross-sectional regressions of holding period returns on duration:

$$
h_{i t}=\alpha_{t}+\gamma_{t} \frac{-D_{i t}}{1+r}+\varepsilon_{i t} .
$$

The model in (19) is estimated separately for each calendar month in our sample. Comparing equation (19) to equation (15), we see that if duration is estimated without error and shocks to expected returns are common across equities, then $\alpha_{t}=0$ and $\gamma_{t}=\Delta r_{t}$. The intuition behind this regression is that we can infer the common shock to expected returns by observing the variation in holding period returns across stocks of differing durations. We make two predictions with respect to the $\gamma$ estimates:

P4: The $\gamma$ estimates from equation (19) are negatively correlated with the holding period returns on the (stock) market portfolio, and

P5: The $\gamma$ estimates from equation (19) are negatively correlated with the holding period returns on long duration bonds.

$P 4$ follows directly from the observation that $\gamma$ measures the change in the common expected return on equities. Increases in the expected return on equities should lead to reductions in equity prices and lower holding period returns on equities. Thus, we should observe a negative correlation between $\gamma$ and the returns on the market portfolio. $P 5$ is more tenuous, since it requires commonality in the expected return shocks across stocks and bonds. If shocks to the risk free rate of return are a significant source of shocks to the expected returns on both stocks and bonds, then there should be a negative correlation between $\gamma$ and long duration bond returns. However, if shocks to expected returns on equities are largely attributable to shocks to the equity premium, then we will still find support for P4, but not necessarily P5. 
Our second procedure for constructing a duration-related factor uses the Fama and French (1993) approach of constructing a mimicking portfolio for duration. That is, we take the difference between the monthly returns on stocks with high versus low durations. This relatively crude factor estimation procedure results in a loss of efficiency relative to the regression procedure. However, it allows us to directly compare our duration factor to the book-to-market factor created by Fama and French (1993). Recall from the previous section that the book-to-market ratio can be interpreted as a duration proxy. Our objective here is to assess the relative ability of our measure of implied equity duration to capture a common factor in expected returns. Accordingly, we test the following two predictions:

P6: A mimicking portfolio for duration captures strong common variation in stock returns,

and

P7: A mimicking portfolio for duration subsumes a mimicking portfolio for book-tomarket in capturing common variation in stock returns.

\section{Data}

Our sample includes all firms with available data from the NYSE, Amex and NASDAQ from 1961 through 1999. Financial statement data are obtained from the COMPUSTAT annual tapes. Earnings are measured using income before extraordinary items (annual data item \#18). Market value of equity is calculated by multiplying per-share price as of the fiscal year end (annual data item \#199) with the number of shares outstanding as of the fiscal year end (data item \#25). Book value of common equity (BV) represents the par value of common stock, treasury stock, additional paid-in capital and retained earnings as of the fiscal year end (annual data item \#60). Observations with negative book value of equity are deleted from the sample. Sales growth is calculated as the one-year discrete growth rate in annual net sales (annual data item \#12). Stock returns are drawn from the Center for Research on Securities Prices (CRSP) daily tape. We use the CRSP value-weighted index with dividends as our measure of the market return. The excess monthly market return is equal to the monthly market return less the one-month Treasury bill rate.

We compute three measures of stock return volatility using weekly holding period returns over a two-year period. First, we compute the standard deviation of total weekly stock returns $(\sigma)$, second we estimate beta $(\beta)$ from a market model regression for each firm, and third we use the market model regression residual standard deviation $\left(\sigma_{f}\right)$. For each firm-year, we compute volatility using both historical and forward data. The historical estimates employ data from the two-year period ending at the end of the fiscal year from which we obtain our financial data. The forward estimates use data from the two-year period beginning at the end of the fiscal year from which we obtain our financial data. 
To be included in our final sample, a firm must have non-missing values for all the required variables from COMPUSTAT and must have at least some of the required return data available on CRSP. This sample consists of 126,870 firm-year observations. Of these observations, data are available to compute at least one of the volatility metrics for 102,684 observations. We also winsorize the one-percent tails of each of the financial ratios computed using the COMPUSTAT data to reduce the influence of extreme outliers.

Finally, we obtain data on monthly percent long-term government bond returns from Ibbotson Associates (1999). We construct our excess long-bond return series by subtracting the one-month Treasury bill rate, measured at the beginning of the month.

\section{Results}

\subsection{Descriptive Statistics}

Panel A of Table 3 reports univariate statistics on our implied equity duration variable. Implied equity duration has a mean of 15.1 years and a standard deviation of 4.1 years. The lower quartile value is 13.3 and the upper quartile value is 17.4. Thus, for most firms duration is somewhat below 19.3 years, which is the duration of the special case where no cash distributions are made in the finite forecast horizon. Therefore, we forecast that most firms will distribute a small proportion of the value represented by their stock price during the 10-year finite forecast period. However, the minimum value of duration is -16.8 years, indicating that there are exceptions. A negative value for duration requires that the present value of the cash flows over the finite forecast horizon exceed the market value of equity. One explanation for such a situation is that the stock is underpriced. An alternative explanation is that our forecasting model has incorrectly forecast that past profitability will continue into the future. At the other extreme, the maximum value of duration is 32.0 years. For duration to be so much greater than 19.3 years, the negative present value of the finite forecast period cash flows must be large relative to the market capitalization.

Panel B of Table 3 reports the correlations between implied equity duration and related financial variables. The correlations are generally strong and are consistently of the expected signs. Implied equity duration is strongly negatively correlated with book-to-market (Pearson $=-0.67 ;$ Spearman $=-0.73$ ) and earnings-to-price (Pearson $=-0.79$; Spearman $=-0.76)$. We also find that implied equity duration is positively correlated with sales growth $($ Pearson $=0.20$; Spearman $=0.19$ ). Ceteris paribus, higher sales growth implies more near-term investment and longer duration. It is also noteworthy that the correlations between book-to-market and earnings-to-price $($ Pearson $=0.57$; Spearman $=0.58$ ) are lower than the respective correlations of each of these variables with duration. In other words, duration summarizes common variation in book-to-market and earnings-to-price. Book-tomarket, earnings-to-price and sales growth have all been proposed as empirical proxies for unidentified common risk factors in stock returns. The correlations in 


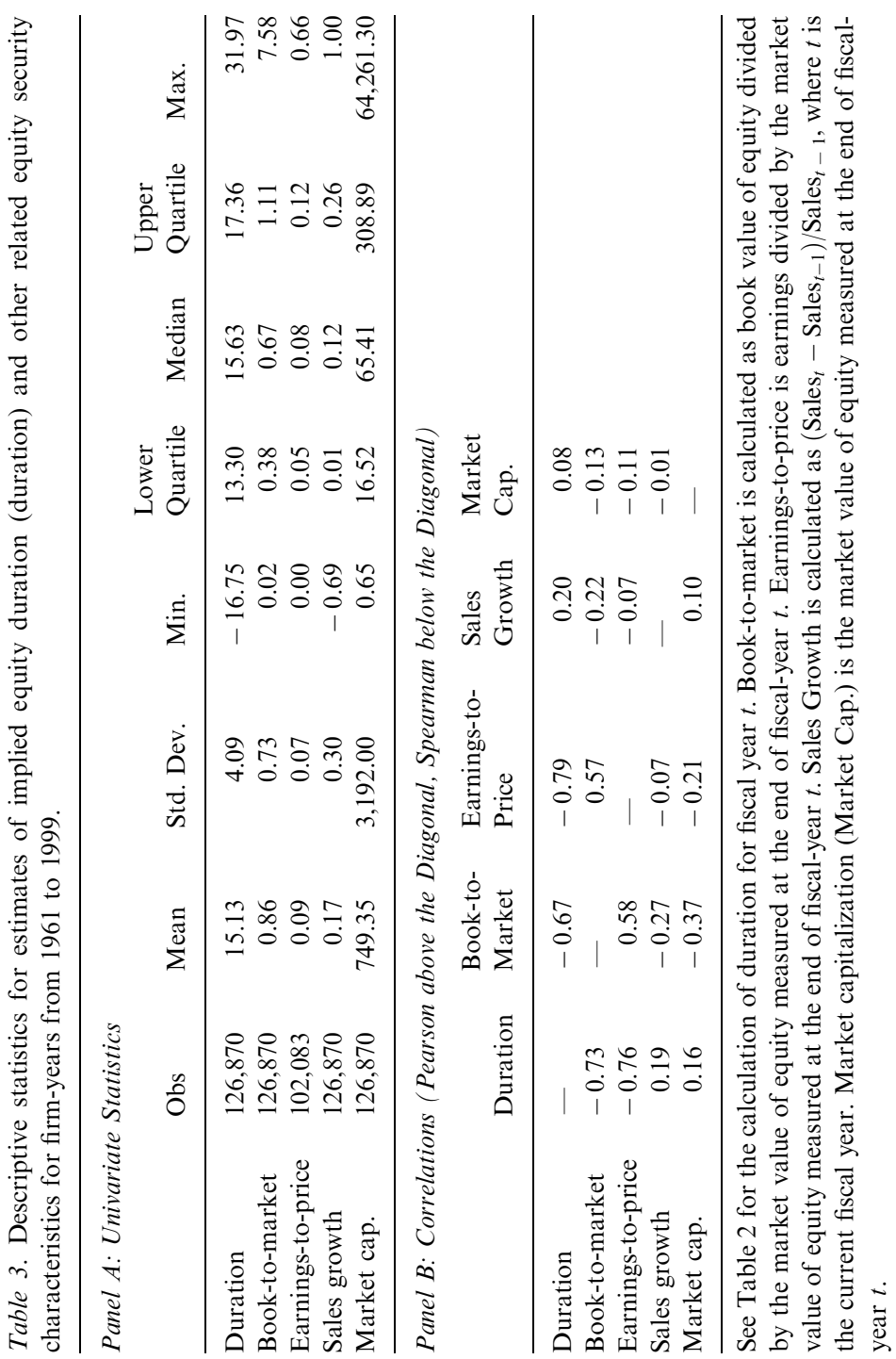


Table 3 are consistent with implied equity duration representing the underlying common factor represented by each of these variables.

\subsection{Volatility Results}

The first three predictions outlined in Section 1.4 concern the relation between implied equity duration and stock return volatility. This section presents the results of tests of these predictions. We begin in Table 4 by providing evidence on the association between implied equity duration and historical stock return volatility. Table 5 then provides evidence on the ability of duration to forecast future stock return volatility.

Panel A of Table 4 presents correlations between our estimates of implied equity duration and estimates of the standard deviation of weekly stock returns. We also report correlations for related financial variables. Consistent with our first prediction, $P 1$, implied equity duration has a strong positive correlation with stock return volatility $($ Pearson $=0.19$, Spearman $=0.23$ ). Book-to-market, earnings-toprice, sales growth and market capitalization also have significant correlations with stock return volatility. However, in the case of book-to-market, earnings-to-price and sales growth, the correlations are much weaker than they are for implied duration. Moreover, the sign of the correlations for these variables are the same as the sign of their correlations with implied equity duration. The results for these variables are therefore consistent with them serving as noisy proxies for duration. For market capitalization, however, the correlations with stock return volatility are negative, and the Spearman correlation is stronger than the corresponding return for implied duration. The strong negative correlations for market capitalization cannot be explained by a duration proxy story, and are probably attributable to the greater cash flow volatility of smaller, less diversified firms.

Panels B and C of Table 4 look at the correlations between implied equity duration and the systematic and firm-specific components of volatility, respectively. Consistent with $P 2$, there is a strong positive correlation between relative duration and beta (Pearson $=0.12$; Spearman $=0.19$ ). The correlations for book-to-market, earnings-to-price and sales growth are somewhat weaker, and are of the same sign as their respective correlations with duration. The results for these variables are again consistent with them serving as noisy proxies for duration. In contrast, the sign of the correlation on market capitalization switches from negative to positive from panel A to panel B. Small firms have higher total volatility, while large firms have higher systematic volatility. This result is consistent with the higher return volatility of small firms arising from higher firm-specific volatility in their underlying cash flows.

Finally, Panel C reports the correlations for the firm-specific component of stock return volatility $\left(\sigma_{f}\right)$. Consistent with $P 3$, there is a strong positive correlation between implied equity duration and $\sigma_{f}($ Pearson $=0.18$; Spearman $=0.22)$. Again, the correlations for book-to-market, earnings-to-price and sales growth are somewhat weaker. The correlation for market capitalization is large and negative, 
Table 4. Correlation between equity volatility and implied equity duration, book-to-market, earnings-toprice, sales growth and size for firm-years from 1961 to 1999.

\begin{tabular}{|c|c|c|c|c|c|}
\hline & Duration & $\begin{array}{l}\text { Book-to- } \\
\text { Market }\end{array}$ & $\begin{array}{l}\text { Earnings-to- } \\
\text { Price }\end{array}$ & $\begin{array}{l}\text { Sales } \\
\text { Growth }\end{array}$ & $\begin{array}{l}\text { Market } \\
\text { Cap. }\end{array}$ \\
\hline Pearson corr of $\sigma$ with & 0.19 & -0.03 & -0.04 & 0.08 & -0.16 \\
\hline Spearman corr of $\sigma$ with & 0.23 & -0.09 & -0.12 & 0.04 & -0.49 \\
\hline Observations & 102,684 & 102,684 & 83,155 & 102,684 & 102,684 \\
\hline \multicolumn{6}{|c|}{ Panel B: Volatility is the Stock Return Beta $[\beta]$} \\
\hline & $\begin{array}{l}\text { Relative } \\
\text { Duration }\end{array}$ & $\begin{array}{l}\text { Book-to- } \\
\text { Market }\end{array}$ & $\begin{array}{l}\text { Earnings-to- } \\
\text { Price }\end{array}$ & $\begin{array}{l}\text { Sales } \\
\text { Growth }\end{array}$ & $\begin{array}{l}\text { Market } \\
\text { Cap. }\end{array}$ \\
\hline Pearson corr of $\beta$ with & 0.12 & -0.10 & -0.06 & 0.07 & 0.06 \\
\hline Spearman corr of $\beta$ with & 0.19 & -0.15 & -0.09 & 0.08 & 0.18 \\
\hline Observations & 102,684 & 102,684 & 83,155 & 102,684 & 102,684 \\
\hline \multicolumn{6}{|c|}{ Panel C: Volatility is the Standard Deviation of Firm-Specific Weekly Stock Returns $\left[\sigma_{f}\right]$} \\
\hline & Duration & $\begin{array}{l}\text { Book-to- } \\
\text { Market }\end{array}$ & $\begin{array}{l}\text { Earnings-to- } \\
\text { Price }\end{array}$ & $\begin{array}{l}\text { Sales } \\
\text { Growth }\end{array}$ & $\begin{array}{l}\text { Market } \\
\text { Cap. }\end{array}$ \\
\hline Pearson corr of $\sigma_{f}$ with & 0.18 & -0.02 & -0.03 & 0.07 & -0.16 \\
\hline Spearman corr of $\sigma_{f}$ with & 0.22 & -0.07 & -0.12 & 0.03 & -0.54 \\
\hline Observations & 102,684 & 102,684 & 83,155 & 102,684 & 102,684 \\
\hline
\end{tabular}

Relative duration for firm $i$ in year $t$ is calculated as Duration Durket duration $\left._{t}\right)$. Market duration is the value-weighted average of all firms with a measure of duration in fiscal year $t$. See Table 2 for the calculation of duration for firm $i$ in fiscal year $t$. Book-to-market is calculated as book value of equity divided by the market value of equity measured at the end of fiscal-year $t$. Earnings-to-price is earnings divided by the market value of equity measured at the end of fiscal-year $t$. Sales Growth is calculated as $\left(\right.$ Sales $_{t}-$ Sales $\left._{t-1}\right) /$ Sales $_{t-1}$, where $t$ is the current fiscal year. Market capitalization (Market Cap.) is the market value of equity measured at the end of fiscal-year $t$.

$\beta$ for firm $i$ for fiscal year $t$ is estimated via a market model regression. The regression is run using weekly returns for a period of two years ending at the end of the fiscal year from which we obtain the data to compute each of the financial ratios. The standard deviation of stock returns $[\sigma]$ is the standard deviation of the weekly returns calculated over the same two-year period. The standard deviation of firm-specific stock returns $\left[\sigma_{f}\right]$ is the standard deviation of the residuals from the market model regression.

All correlations are significant at the 0.0001 level.

corroborating our earlier conjecture that the higher return volatility of small firms arises from higher firm-specific cash flow volatility.

Table 5 investigates the ability of implied equity duration to forecast future stock return volatility. We use the same measures of stock return volatility as Table 4, but the measures are now for the two years following the computation of implied equity duration. Instead of reporting correlations, we report regressions of our volatility metrics on implied equity duration. This approach allows us to include lagged values of the volatility metrics as competing explanatory variables. For our estimates of 
Table 5. Forecasting ability of implied equity duration with respect to equity security volatility for firmyears from 1961 to 1997.

Panel A: Volatility is Standard Deviation of Stock Returns $[\sigma]$

\begin{tabular}{lcccc} 
& Intercept & Duration & Volatility $(t)$ & Adj. $R^{2}$ \\
\hline Model 1 & & & & \\
Coefficient & 0.039 & 0.002 & & \\
Standard error & 0.000 & 0.000 & & \\
$t$-statistic & 95.39 & 60.15 & & \\
Model 2 & & & & 0.46 \\
Coefficient & 0.009 & 0.001 & 0.003 & \\
Standard error & 0.000 & 0.000 & 236.85 & \\
$t$-statistic & 26.91 & 34.08 & & \\
\hline
\end{tabular}

Panel B: Volatility is Stock Return Beta $[\beta]$

\begin{tabular}{lcccc} 
& Intercept & $\begin{array}{l}\text { Relative } \\
\text { Duration }\end{array}$ & Volatility $(t)$ & Adj. $R^{2}$ \\
\hline Model 1 & & & & 0.02 \\
Coefficient & 0.580 & 0.3177 & & \\
Standard error & 0.008 & 0.008 & & 0.19 \\
$t$-statistic & 71.76 & 40.35 & 0.39 & \\
Model 2 & 0.329 & 0.197 & 0.00 & \\
Coefficient & 0.008 & 0.008 & 120.80 & \\
Standard error & 41.21 & 25.85 & & \\
$t$-statistic & &
\end{tabular}

Panel C: Volatility is Standard Deviation of Firm-Specific Stock Returns $\left[\sigma_{f}\right]$

\begin{tabular}{lcccc} 
& Intercept & Duration & Volatility $(t)$ & Adj. $R^{2}$ \\
\hline Model 1 & & & & \\
Coefficient & 0.036 & 0.002 & & 0.04 \\
Standard error & 0.000 & 0.000 & & \\
$t$-statistic & 80.18 & 54.91 & & \\
Model 2 & & & & 0.41 \\
Coefficient & 0.009 & 0.001 & 0.003 & \\
Standard error & 0.000 & 0.000 & 215.28 & \\
$t$-statistic & 23.12 & 30.82 & & \\
\hline
\end{tabular}

The number of observations in the Model 1 regressions is 83,785 and in Model 2 regression is 71,491.

Relative Duration for firm $i$ in year $t$ is calculated as Duration ${ }_{i t} /$ (Market duration). Market duration is the value-weighted average of all firms with a measure of duration in fiscal year $t$. See Table 2 for the calculation of duration for firm $i$ in fiscal year $t$.

$\beta$ for firm $i$ for fiscal year $t$ is estimated via a market model regression. The regression is run using weekly returns for a period of two years starting following the year from which we obtain the data to compute each of the financial ratios. The standard deviation of stock returns $[\sigma]$ is the standard deviation of the weekly returns calculated over the same two-year period. The standard deviation of firm-specific stock returns $\left[\sigma_{f}\right]$ is the standard deviation of the residuals from the market model regression.

All correlations are significant at the 0.0001 level.

Model 1: Volatility $(t+1)=\alpha+\delta$ Duration $(t)$

Model 2: $\operatorname{Volatility}(t+1)=\alpha+\delta$ Duration $(t)+\chi \operatorname{Volatility}(t)$ 
implied equity duration to be useful from a forecasting perspective, they must have incremental explanatory power over lagged values of the volatility metrics.

Panel A of Table 5 provides evidence of the hypothesized positive relation between implied equity duration and future stock return volatility. The results for Model 1 indicate that implied equity duration is positively related to the future standard deviation of stock returns. The results for Model 2 indicate that implied equity duration still loads with a significant positive coefficient when we include the lagged value of the standard deviation of stock returns in the regression. To gauge the economic significance of this result, we note that the average standard deviation of weekly stock returns in our sample is 0.065 . The regression coefficient on duration implies that two stocks with the same past volatility, and a 10-year spread in implied equity duration will have a $0.01(0.001 \times 10)$ spread in future volatility, representing over $15 \%$ of the sample-wide average volatility of 0.065 . Panels B and C confirm that the positive relation between implied equity duration and future volatility extends to both the systematic and firm-specific components of return volatility. Thus, implied equity duration is incrementally useful in forecasting future stock return volatility and its components.

In summary, we provide three key findings concerning the relation between implied equity duration and stock return volatility. First, we find strong evidence of the hypothesized positive relation between implied equity duration and stock return volatility. Second, we show that the relations of book-to-market and earnings-toprice to stock return volatility are consistent with these variables serving as noisy proxies for duration. Finally, we show that implied equity duration is incrementally useful over past stock return volatility in forecasting future stock return volatility.

\subsection{Common Factor Results}

Our next set of tests examines whether duration represents a significant common factor in stock returns. In Section 1.4, we derived the following cross-sectional relation between monthly holding period returns and duration (see equation (19)):

$$
h_{i t}=\alpha_{t}+\gamma_{t} \frac{-D_{i t}}{1+r}+\varepsilon_{i t} .
$$

The coefficient $\gamma_{t}$ from these monthly cross-sectional regressions provides an estimate of the change in expected return $(\Delta r)$ for month $t$. We predict that $\gamma_{t}$, our estimate of $(\Delta r)$, will be negatively correlated with the excess monthly market return. Empirical estimation of this regression is subject to several specification issues. First, the relation is only approximate and not valid for large values of $\Delta r$ (the convexity property described in Note 2). This should not create a serious problem, since our estimation uses monthly data, and monthly changes in expected return are unlikely to be large enough to create serious violations of the linearity assumption. Second, stock returns are also determined by cash flow shocks. This omitted variable has the potential to bias our $\gamma_{t}$ estimates if cash flow shocks are correlated with expected 
return shocks. Third, there is an errors-in-variables problem arising from our use of empirical estimates for duration $(D)$ and expected returns $(r)$. This problem will cause the intercept in the regression to be positive and the slope to be biased toward zero, thus understating the magnitude of the estimated changes in expected returns. We have no a priori reasons to expect that any of these specification issues will bias our empirical tests in favor of our predictions.

Panel A of Table 6 and Figure 1(a) report the distributional properties of our estimates of change in expected return on equities $(\Delta r)$. The $\Delta r$ estimates range from a low of $-0.82 \%$ to a high of $1.51 \%$. The low of $-0.82 \%$ occurred in October of 1969 , a month in which the market rose by over $5 \%$. The high of $1.51 \%$ occurred in June of 1970 , a month when the market fell by over $11 \%$. During the best month for the market in our sample period (October 1974), the market rose by over $16 \%$ and $\Delta r$ was less than $-0.5 \%$. Conversely, during the worst month (October 1987), the market fell by over $22 \%$ and $\Delta r$ exceeded $0.5 \%$. Thus, our analysis suggests that our estimates of $\Delta r$ exhibit substantial temporal variation. Moreover, significant shocks to expected returns are associated with significant shocks to holding period returns of the opposite sign, consistent with the predictions of basic valuation theory. Figure 1(a) indicates that the distribution of $\Delta r$ is right-skewed (skewness $=0.54$ )

Table 6. Relation between estimated changes in expected returns $(\Delta r)$, market returns and other common factors in stock returns for firm-years from 1962 to 1998.

\begin{tabular}{|c|c|c|c|c|c|c|c|c|}
\hline & Obs. & Mean & $\begin{array}{l}\text { Std. } \\
\text { Dev. }\end{array}$ & Min & Low & Median & Upper & Max \\
\hline $\begin{array}{l}\text { Excess market } \\
\text { return (RM-RF) }\end{array}$ & 420 & 0.53 & 4.30 & -22.82 & -1.95 & 0.72 & 3.28 & 16.00 \\
\hline $\begin{array}{l}\text { Excess long bond } \\
\text { return (TERM) }\end{array}$ & 420 & 0.11 & 3.02 & -8.69 & -1.63 & -0.02 & 1.82 & 12.02 \\
\hline $\begin{array}{l}\text { Change in expected } \\
\text { return }(\Delta r)\end{array}$ & 420 & 0.05 & 0.23 & -0.82 & -0.06 & 0.05 & 0.18 & 1.51 \\
\hline $\begin{array}{l}\text { Duration factor } \\
\text { (HDMLD) }\end{array}$ & 420 & -0.50 & 2.61 & -8.69 & -2.01 & -0.56 & 1.01 & 9.96 \\
\hline Size factor (SMB) & 420 & 0.27 & 2.81 & -10.01 & -1.42 & 0.09 & 1.98 & 9.06 \\
\hline $\begin{array}{r}\text { Book-to-market } \\
\text { factor (HML) }\end{array}$ & 420 & 0.41 & 3.17 & -14.22 & -2.39 & -0.58 & 1.34 & 16.50 \\
\hline \multicolumn{9}{|c|}{ Panel B: Correlations (Pearson above the Diagonal, Spearman below the Diagonal) } \\
\hline & RM-RF & TERM & $\Delta r$ & HDMLD & SMB & HML & & \\
\hline RM-RF & - & $\begin{array}{l}0.33 \\
(0.0001)\end{array}$ & $\begin{array}{l}-0.45 \\
(0.0001)\end{array}$ & $\begin{array}{l}0.35 \\
(0.0001)\end{array}$ & $\begin{array}{l}0.31 \\
(0.0001)\end{array}$ & $\begin{array}{l}-0.24 \\
(0.0001)\end{array}$ & & \\
\hline TERM & $\begin{array}{l}0.36 \\
(0.0001)\end{array}$ & - & $\begin{array}{l}-0.08 \\
(0.1155)\end{array}$ & $\begin{array}{l}0.01 \\
(0.7888)\end{array}$ & $\begin{array}{l}-0.12 \\
(0.0119)\end{array}$ & $\begin{array}{l}-0.02 \\
(0.6531)\end{array}$ & & \\
\hline$\Delta r$ & $\begin{array}{l}-0.45 \\
(0.0001)\end{array}$ & $\begin{array}{l}-0.06 \\
(0.2000)\end{array}$ & - & $\begin{array}{l}-0.73 \\
(0.0001)\end{array}$ & $\begin{array}{l}-0.28 \\
(0.0001)\end{array}$ & $\begin{array}{l}0.57 \\
(0.0001)\end{array}$ & & \\
\hline HDMLD & $\begin{array}{l}0.33 \\
(0.0001)\end{array}$ & $\begin{array}{l}0.01 \\
(0.9428)\end{array}$ & $\begin{array}{l}-0.72 \\
(0.0001)\end{array}$ & - & $\begin{array}{l}0.17 \\
(0.0001)\end{array}$ & $\begin{array}{l}-0.77 \\
(0.0004)\end{array}$ & & \\
\hline SMB & $\begin{array}{l}0.25 \\
(0.0001)\end{array}$ & $\begin{array}{l}-0.10 \\
(0.0177)\end{array}$ & $\begin{array}{l}-0.25 \\
(0.0001)\end{array}$ & $\begin{array}{l}0.18 \\
(0.0001)\end{array}$ & - & $\begin{array}{l}-0.05 \\
(0.0001)\end{array}$ & & \\
\hline HML & $\begin{array}{l}-0.26 \\
(0.0001)\end{array}$ & $\begin{array}{l}-0.06 \\
(0.2019)\end{array}$ & $\begin{array}{l}0.57 \\
(0.0001)\end{array}$ & $\begin{array}{l}-0.76 \\
(0.0001)\end{array}$ & $\begin{array}{l}-0.12 \\
(0.0137)\end{array}$ & - & & \\
\hline
\end{tabular}


Table 6. Continued.

\begin{tabular}{|c|c|c|c|c|c|c|}
\hline & $\begin{array}{l}\text { of the Exc } \\
\text { Intercept }\end{array}$ & $\Delta r$ & $\begin{array}{l}(R M-R F) \\
\text { HDMLD }\end{array}$ & SMB & HML & Adj. $R^{2}$ \\
\hline \multicolumn{7}{|l|}{ Model 1} \\
\hline Coefficient & 0.003 & & & 0.456 & -0.306 & 0.142 \\
\hline Standard error & 0.002 & & & 0.069 & 0.061 & \\
\hline$t$-statistic & 1.46 & & & 6.57 & -4.98 & \\
\hline \multicolumn{7}{|l|}{ Model 2} \\
\hline Coefficient & 0.009 & -7.409 & & 0.299 & -0.008 & 0.237 \\
\hline Standard error & 0.002 & 1.019 & & 0.068 & 0.071 & \\
\hline$t$-statistic & 4.53 & -7.27 & & 4.34 & -0.11 & \\
\hline \multicolumn{7}{|l|}{ Model 3} \\
\hline Coefficient & 0.007 & & 0.545 & 0.387 & 0.038 & 0.182 \\
\hline Standard error & 0.002 & & 0.118 & 0.069 & 0.096 & \\
\hline$t$-statistic & 3.42 & & 4.63 & 5.58 & 0.40 & \\
\hline
\end{tabular}

The common factors are the market return, long-term bond return, change in expected return, duration, size, and book-to-market. Reported numbers in Panel A are percentages. In Panel B Pearson Correlation Coefficients are reported in the upper right diagonals and Spearman Correlation Coefficients in the lower left diagonal ( $p$-values in parentheses). The time period is from July 1962 to June 1998 and consists of 420 months. The excess long-bond return (TERM) is computed as the difference between the long-run government bond return and the one-month Treasury bill return. The excess market return (RM-RF) is computes as the difference between the CRSP value-weighted index monthly return and the one-month Treasury bill return. The change in the expected return $(\Delta r)$ is the estimate of $\gamma$ from cross sectional regressions of the form: $h_{i t}=\alpha_{t}+\gamma_{t}\left(-D_{i t} /(1+r)\right)+\varepsilon_{i t}$.

SMB (small minus big), the return on the mimicking portfolio for the common size factor in stock returns, is the difference each month between the simple average of the percent returns on the three smallstock portfolios $(\mathrm{S} / \mathrm{L}, \mathrm{S} / \mathrm{M}$, and $\mathrm{S} / \mathrm{H})$ and the simple average of the returns on the three big-stock portfolios $(\mathrm{B} / \mathrm{L}, \mathrm{B} / \mathrm{M}$, and $\mathrm{B} / \mathrm{H})$. HML (high minus low), the return on the mimicking portfolio for the common book-to-market equity factor in returns, is the difference each month between the simple average of the returns on the two high-BE/ME portfolios $(\mathrm{S} / \mathrm{H}$ and $\mathrm{B} / \mathrm{H})$ and the average of the returns on the two low-BE/ME portfolios ( $\mathrm{S} / \mathrm{L}$ and $\mathrm{B} / \mathrm{L}$ ). HDMLD (high minus low), the return on the mimicking portfolio for the duration factor in returns, is the difference each month between the simple average of the returns on the two high-duration portfolios (S/HD and $\mathrm{B} / \mathrm{HD}$ ) and the average of the returns on the two lowduration portfolios $(\mathrm{S} / \mathrm{LD}$ and $\mathrm{B} / \mathrm{LD})$.

and highly leptokurtic (kurtosis $=5.04$ ). It is well known that monthly market returns are left skewed and leptokurtic. Our results suggest that these properties in returns can be attributed, at least in part, to related properties in the distribution of shocks to expected returns.

$P 4$ and $P 5$ predict a negative correlation between $\Delta r$ and both the market return and the excess long bond return. Panel B of Table 6 reports these correlations. For the market return, both the Pearson and Spearman correlations are strongly negative ( -0.45 for each) and support $P 4$. Visual confirmation of the negative correlation between our estimates of $\Delta r$ and the market return are provided in Figures 1(b) (monthly realizations) and 1(c) (12-month moving averages). For the long bond return, however, the correlations are negative but are not statistically significant. This latter result is somewhat puzzling. One explanation for the result is that shocks 
to the risk-free component of expected equity returns are extremely small relative to shocks to the equity premium. ${ }^{8}$ However, the relatively strong correlation between the market return and the long-bond return is difficult to reconcile with this explanation. Alternatively, shocks to the risk-free rate may be correlated with shocks to short-term cash flows that are greater for short duration equities and hence confound the reported correlations.
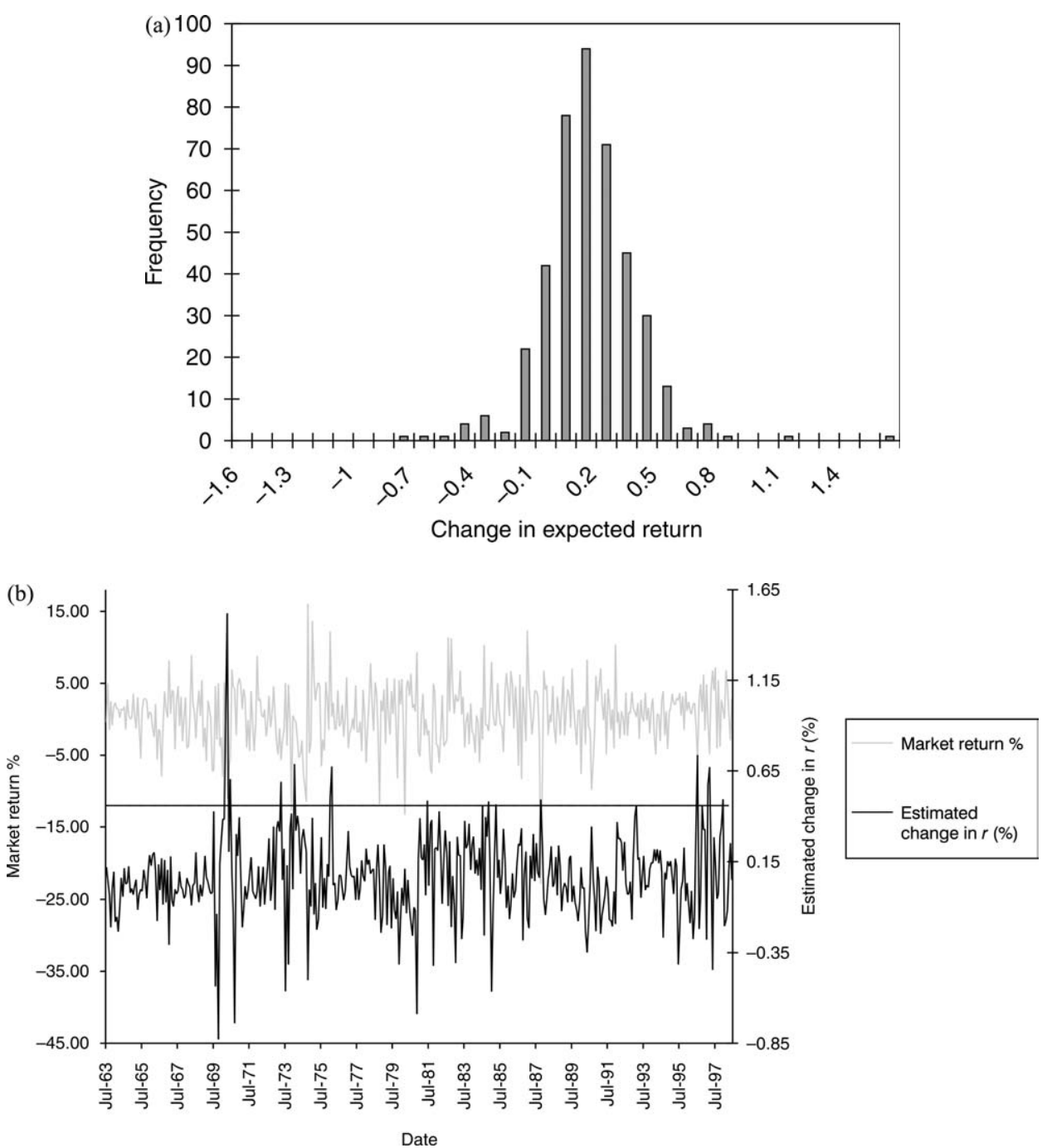

Figure 1. (a) Histogram of monthly estimates of change in expected return. The figure is a graphical illustration of monthly estimates of the change in expected return $(\Delta r)$ where the change in expected return is the $\gamma$ coefficient from the regression: $h_{i t}=\alpha_{t}+\gamma_{t}\left(-D_{i t} /(1+r)\right)+\varepsilon_{i t}$. (b) Monthly data for the market return and the estimated change in expected return. (c) Twelve month moving average monthly data for the market return and the estimated change in expected return. 


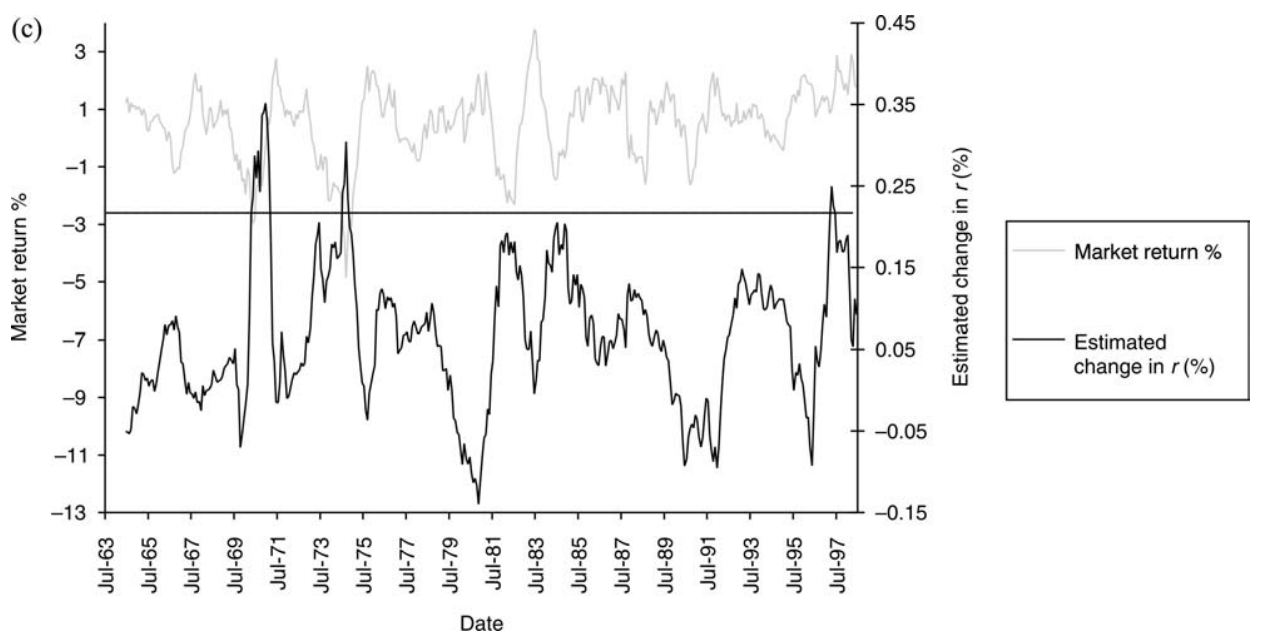

Figure 1. Continued.

We next test predictions $P 6$ and $P 7$. For these tests we form a duration mimicking portfolio (HDMLD) by taking the difference between the returns on stocks with high duration and the returns on stocks with low duration each month in the same manner as Fama and French (1993) use to calculate their book-to-market mimicking portfolio (HML). We also create a size factor (SMB) and a book-to-market factor (HML) using the procedures described in Fama and French (1993). ${ }^{9}$

Panel B of Table 6 compares the correlation of HDMLD with the market return and the excess bond return. Consistent with P6, HDMLD has a strong positive correlation with the market return. This correlation is stronger than either HML or SMB. But it is $\Delta r$ that has the strongest correlation with the market return. This is consistent with $\Delta r$ representing our most efficient estimate of the common factor in returns related to duration. As would be expected, $\Delta r$ is highly negatively correlated with our mimicking portfolio for duration (Pearson $=-0.73$, Spearman $=-0.72$ ) and positively correlated with the mimicking portfolio for book-to-market $($ Pearson $=0.57$, Spearman $=0.57$ ).

Panel C of Table 6 provides tests of P7. Model 1 indicates that $14 \%$ of the variation in excess monthly market returns is explained by the SMB and HML mimicking factors. In Models 2 and 3, we add duration-related factors ( $\Delta r$ and HDMLD). The results indicate that our duration factors subsume the explanatory power of HML. Both $\Delta r$ and HDMLD load with a significant coefficient, while the coefficient on HML falls close to zero and is no longer statistically significant. This is consistent with $P 7$. The $R^{2}$ is highest (24\%) when $\Delta r$ is used as the duration factor (Model 2). This result is comforting, because the $\Delta r$ estimates are derived from the underlying theoretical relation between duration and returns rather than an ad hoc mimicking factor. Overall, these results are consistent with book-to-market and its associated HML factor serving as noisy proxies for equity duration-related effects in 
stock returns. Our refined measures of duration lead to significant improvements in explanatory power.

\subsection{Descriptive Evidence on the Equity Yield Curve}

We complete our empirical analysis by reporting descriptive evidence on the equity yield curve. A yield curve plots the yield on a class of securities as a function of the number of years to maturity, and is a common feature of fixed income security analysis. At a given point in time, the shape of the yield curve is influenced by expectations about future short-term interest rates. Averaged over longer periods of time, the yield curve can provide information about the preferred investment horizons of investors. A risk averse investor will pay a premium to avoid the risk associated with the uncertainty in realized returns that results from investing in a security with a maturity that differs from the investor's desired horizon. The longrun average upward slope of the yield curve for treasury securities is the empirical basis for the liquidity preference theory, which holds that investors with short horizons dominate the market for Treasuries. There is, however, no corresponding evidence concerning the preferred investment horizons of equity investors.

The construction of an equity yield curve is more complicated than the construction of a Treasury bond yield curve for two reasons. First, in constructing a yield curve, one would ideally like to compute the "pure" curve, using securities that make a single "bullet" payment at a specific maturity date. Under such circumstances, there is no ambiguity concerning the maturity of the security. In computing the yield curve for Treasuries, the existence of coupon payments slightly complicates this process. This problem is further complicated for equities, since the payouts from an equity security are typically realized gradually over long periods of time. We therefore use our measure of implied equity duration to approximate the maturity of an equity security.

The second problem is that without a fixed schedule of future payoffs, it is difficult to compute the implied yield on an equity security. In this respect, recall that our empirical technique for estimating the terminal cash flows on an equity security involved assuming a constant yield and solving for the implied terminal cash flows. Thus, it would be circular to impute the yield from our assumed cash flows. Instead, we rely on rational expectations and assume that anticipated and realized yields will converge when averaged over long periods of time. Accordingly, we estimate anticipated yields on securities of varying durations by computing the average realized annual returns on securities in various duration categories. We compute realized returns over the 12-month period beginning four months after the end of the fiscal year from which we obtain the financial inputs for our duration computation. This ensures that the information we use to compute implied equity duration would have been available to market participants. The resulting sample consists of 110,072 annual return observations. We then partition these observations into six duration categories: $<1$ year (4,027 observations), $1-5$ years (3,904 observations), 6-10 years 


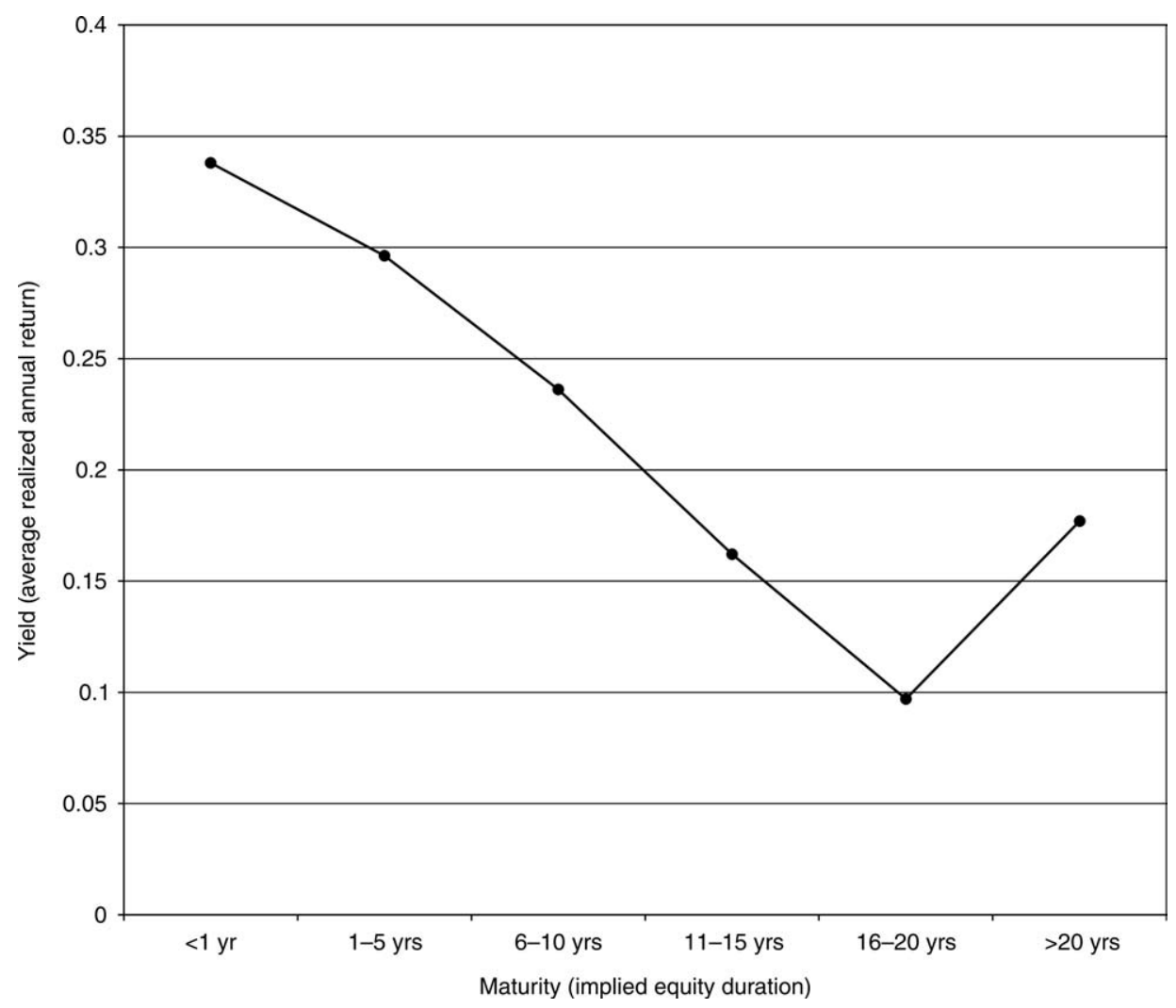

Figure 2. Equity yield curve. Observations are sorted into categories based on implied equity duration. Average annual buy-hold returns are computed starting four months after the fiscal year-end for each duration category and plotted to give the equity yield curve.

(12,875 observations), $11-15$ years (42,201 observations), 6-20 years $(39,808$ observations) and $>20$ years ( 7,157 observations).

Figure 2 reports the average realized future annual returns for each duration category. There is a distinctive downward sloping yield curve over the first 20 years, with realized future returns declining monotonically from $33.8 \%$ for the lowest duration category to $9.7 \%$ for the 16-20 year category. Throughout the paper, we have argued that longer duration is synonymous with increased risk. Why then would investors require a higher return for holding low duration equities? We discuss two alternative explanations below.

The first explanation for the downward sloping equity yield curve is that investors have a preference for long duration equities, and so require a premium for holding short duration equities. This contrasts with fixed income securities, where we typically see an upward sloping yield curve, indicating a preference for short duration securities. At first glance, these results seem somewhat difficult to reconcile, but they are consistent with the popular investment maxim "stocks for the long run." 
Investors with short horizons may view the reinvestment risk from receiving dividends and the transaction costs involved in reinvesting dividends as particularly costly for equities. Facing these costs, they may prefer to invest in short-term bonds rather than low duration equities.

Our results for the equity yield curve are closely related to the "book-to-market" effect in stock returns. Recall that implied equity duration and book-to-market are negatively correlated. Thus, given that book-to-market is positively related to future returns, it should come as no surprise that duration is negatively related to future returns. What we offer is a new explanation for these results. Investors in equities have a preference for locking in long holding period returns, and so require a premium for holding short duration equities.

Our evidence suggesting that equities are priced by investors with multi-year investment horizons has important implications for existing empirical tests of asset pricing theories. Existing research typically uses short holding period returns (i.e., weekly, monthly or annual). Much of the systematic volatility in stock returns over such short holding periods is attributable to expected return shocks (Campbell and Mei, 1993). However, our evidence suggests that it is premature to claim that this volatility represents a source of risk that should be priced by investors. It is largely irrelevant to investors with long investment horizons. Indeed, the long duration equities, which have the most short-term price volatility, represent the least risky securities for investors with long investment horizons. Investing in long duration equities allows these investors to lock in the current expected return, and hence immunize themselves from future expected return shocks. Investing in short duration equities exposes investors to the reinvestment risk associated with rolling over their investments at uncertain future rates of return.

The above explanation for the downward sloping yield curve ties in closely with recent research examining the implications of intertemporal asset pricing models for risk and valuation. Brennan and Xia (2003) develop an intertemporal asset-pricing model and show that beta is always increasing with the duration of the underlying cash flows on a security. However, when examining the relation between expected returns and duration, they find that expected returns can be increasing, decreasing or non-monotone functions of duration. Campbell and Vuolteenaho break equity betas into two components, one reflecting cash flow shocks and the other reflecting expected return shocks. They note that intertemporal asset pricing theory suggests that the former should be priced more highly than the latter. Empirically, they show that "value" stocks with high book-to-market ratios have relatively high cash flow betas, and this can explain their higher average returns. The common theme emerging from these papers is that the expected return implications of beta risk arising from discount rate shocks are very different from those arising from cash flow shocks.

An alternative explanation for the negative relation between duration and future stock returns is investor irrationality. Lakonishok et al. (1994) suggest that investors are overly optimistic about the growth prospects of "glamour" stocks and bid the prices of these securities up to irrationally high levels. Subsequently, these stocks fail to live up to expectations, resulting in low future stock returns. Such glamour stocks 
will have low book-to-market ratios and long implied equity durations, because investor exuberance drives their market prices high relative to near-term fundamentals. Daniel et al. $(1998,2001)$ extend this line of reasoning by developing models in which individuals are overconfident about private signals and overreact to such signals. A key implication of their models is that the positive relation between fundamental-to-price ratios (such as book-to-market) and future stock returns stems from investor misvaluation. Our measure of implied equity duration is negatively related to fundamental-to-price ratios, and so their models also predict the negative relation between duration and future stock returns. More broadly under this explanation, expected return shocks can be thought of as shifts in investor sentiment, with the prices of long duration "glamour" stocks being the most sensitive to such shifts (see also Baker and Wurgler, 2003).

\section{Conclusion}

In this paper, we develop a procedure for estimating equity duration using financial statement information. We show that the standard empirical predictions and results for bond duration hold for our measure of equity duration and that equity duration captures an important common factor in stock returns. Moreover, we show how our measure of equity duration can be used to forecast equity risk and calibrate expected return shocks. Nevertheless, we acknowledge that our procedure for estimating equity duration, while parsimonious, is relatively crude. Improvements in the procedure should lead to more accurate and useful measures of equity duration.

Our results suggest that the book-to-market ratio provides a crude proxy for equity duration, and that the Fama and French (1993) book-to-market factor can be interpreted as a noisy duration factor. Fama and French (1995) present loose arguments to the effect that their book-to-market factor captures a financial distress factor. We present a tighter set of arguments and accompanying empirical results indicating that a duration-related factor represents a more plausible explanation.

We also examine the relation between implied equity duration and future stock returns, which we refer to as the equity yield curve. The yield curve for fixed income securities is typically upward sloping, suggesting that investors require a "liquidity" premium for holding long duration securities. In contrast, we find that the equity yield curve is downward sloping. We consider two possible explanations for this result. First, investors may prefer to hold long duration equities because they have long investment horizons and wish to immunize themselves from reinvestment risk arising from expected return shocks. Recent work by Brennan and Xia (2003) and Campbell and Vuolteenaho (2003) also concludes that risk arising from expected return shocks is priced very differently from risk arising from cash flow shocks. Alternatively, investors may express an irrational preference for certain stocks due to behavioral biases such as overconfidence (e.g., Lakonishok et al. (1994), Daniel et al. $(1998,2001))$. Under this explanation, the relation between misvaluation and duration arises because investors bid up the prices of certain stocks to irrationally 
high levels relative to current fundamentals, causing them to have long implied equity durations.

Finally, our measure of implied equity duration provides a natural and defensible ranking of equities' style characteristics on the value/growth dimension that is popular among practitioners. Currently, index providers such as Standard and Poor's, Dow Jones and Russell compete to provide the "best" indices of value and growth stocks. ${ }^{10}$ Yet their growth and value classifications are based on ad hoc reasoning and data-motivated statistical procedures. By combining information about expected growth, expected profitability and current stock price into a single and rigorously developed measure, implied equity duration provides an attractive alternative to the ad hoc measures of value and growth commonly proposed by practitioners.

\section{Acknowledgments}

We are grateful for the comments of Charles Lee (Editor), Marlene Plumlee (the discussant at the 2003 AAA meetings), Pedro Santa-Clara (the discussant at 2003 RAST conference), Nejat Seyhun, William Sharpe, K.R. Subramanyam and workshop participants at UC Berkeley, Emory University, London Business School, University of Michigan, MIT, UCLA, University of Southern California, the 2003 RAST conference, and the 2002 Factset PMW Conference. Thanks also to Paul Michaud for programming assistance. Sloan and Dechow acknowledge financial support provided by the Michael A. Sakkinen Research Scholar Fund at the University of Michigan Business School.

\section{Notes}

1. Lanstein and Sharpe (1978) document a common factor in stock returns related to equity duration for a small sample of stocks on which they have analyst forecasts of dividends. We develop a procedure to compute equity duration that does not require analyst forecasts of dividends and, using a much larger sample, document more extensive and robust empirical results. Other papers that consider equity duration and security risk but are less closely related to our analysis include Gould and Sorensen (1986), Leibowitz (1986), Leibowitz and Kogelman (1993), Bernstein (1995) and Cornell (1999).

2. This linear relation is an approximation based on a one-term Taylor series expansion of a bond's price as a function of its yield, divided by its price. The Taylor series can be used to approximate the bond price to any level of accuracy. The two-term series expansion incorporates convexity (the second derivative, $\left.\partial^{2} P / \partial r^{2}\right)$.

3. This identity requires the "clean surplus" assumption: the book value of equity only increases with earnings and equity issuances and decreases with dividends and equity repurchases. In practice, there are some minor violations of this relation, such as foreign currency translation adjustments and unrealized gains and losses on marketable securities. These violations are not expected to introduce any systematic biases.

4. Sales growth rates for US equities have averaged around $10 \%$ over the past 40 years (see Nissim and Penman, 2001). This period, however, has been one of unprecedented growth for US equity markets, and the long-run macroeconomic growth rate provides a more plausible ex ante estimate of long-run sales growth. 
5. A commonly made argument is that all future equity distributions must be made on a pro-rata basis (i.e., dividends and rights issues) rather than on a targeted basis (i.e., stock repurchases, seasoned equity offerings) for our duration predictions to translate from the firm-wide level to the individual shareholder level. This is a misconception, because expected return shocks affect the value of all shares identically, regardless of the holder's intent to participate in any future targeted distributions. The reason for this is that any such distributions are made at prevailing market prices, and these market prices reflect any intervening expected return shocks.

6. For example, if we take a typical long-duration stock based on the constant expected returns assumption, we find that we would have to raise the expected return to over $100 \%$ in order to give it the same duration as a typical low duration stock. The interested reader can verify these computations using the data for Amazon.com and Alaska Air Group that is provided in Table 2.

7. We also replicated our results using a constant expected return on equity ranging from 8 to $18 \%$. A lower (higher) expected return increases (decreases) the average duration of the entire sample, but has little impact on the relative rankings of duration across securities. Therefore, all of our key results are robust with respect to changing the level of the expected return.

8. Brennan and Xia (2003) present calibrations consistent with this conjecture. They develop and calibrate a parsimonious intertemporal capital asset pricing model. A key conclusion emerging from their analysis is that volatility due to variation in the equity premium is more important than volatility due to variation in the risk free rate.

9. Our timing conventions for computing portfolio returns follow those in Fama and French (1993). If we are computing returns for portfolios formed on financial data from year $t-1$, then we compute monthly holding period returns from July of year $t$ through June of year $t+1$. We compute excess returns for each of our stock portfolios by subtracting the one-month Treasury bill rate, measured at the beginning of the month. Six portfolios are formed from sorts on size and book-to-market. Two size groupings (S and B) are formed around the NYSE median and three book-to-market groupings $(\mathrm{L}, \mathrm{M}$ and $\mathrm{H})$ are formed around the NYSE 30th and 70th percentiles. Six value-weighted portfolios are constructed from the intersection of these groupings $(\mathrm{S} / \mathrm{L}, \mathrm{S} / \mathrm{M}, \mathrm{S} / \mathrm{H}, \mathrm{B} / \mathrm{L}, \mathrm{B} / \mathrm{M}, \mathrm{B} / \mathrm{H})$. The mimicking factor for size (SMB) is constructed by taking the difference, each month, between the simple average of the returns on the three small-stock portfolios and the three big-stock portfolios. Similarly, the mimicking factor for book-to-market (HML) is the difference, each month, between the simple average of the returns on the two high-book-to-market portfolios and the two low-book-tomarket portfolios. For HDMLD we form three duration groupings (LD, MD and HD) around the NYSE 30th and 70th percentiles. Six value-weighted portfolios are constructed from the intersection of two size groups and the three duration groups ( $/ \mathrm{LD}, \mathrm{S} / \mathrm{MD}, \mathrm{S} / \mathrm{HD}, \mathrm{B} / \mathrm{LD}, \mathrm{B} / \mathrm{MD}, \mathrm{B} / \mathrm{HD}$ ). The mimicking factor for duration (HDMLD) is the difference, each month, between the simple average of the returns on the two high duration portfolios and the two low duration portfolios.

10. Standard and Poor's uses the BARRA classification of value versus growth, which is based on bookto-market. Dow Jones and Russell use more complex measures that combine more than one indicator of value and growth. A comparison of the alternative approaches is provided at: http:// www.djindexes.com/downloads/US_Style_broch.pdf.

\section{References}

Amihud, Y. and H. Mendelson. (1986). “Asset Pricing and the Bid-Ask Spread.” Journal of Financial Economics 17, 223-260.

Baker, M. and J. Wurgler. (2003). "Investor Sentiment and the Cross-section of Stock Returns." Working paper, Harvard University.

Bernstein, R. (1995). Style Investing: Unique Insights into Equity Management. Hoboken, NJ: John Wiley and Sons.

Brennan, M. and Y. Xia. (2003). "Risk and Valuation Under an Intertemporal Capital Asset Pricing Model." Working paper, University of Pennsylvania. 
Campbell, J. and J. Mei. (1993). "Where Do Beta Come From? Asset Price Dynamics and the Sources of Systematic Risk." The Review of Financial Studies 6, 567-592.

Campbell, J. and R. Shiller. (1988). "Stock Prices, Earnings and Expected Dividends." Journal of Finance $43,661-677$.

Campbell, J. and T. Vuolteenaho. (2003). "Bad Beta, Good Beta." Working paper, National Bureau of Economic Research.

Cornell, B. (1999). "Risk, Duration, and Capital Budgeting: New Evidence on Some Old Questions." Journal of Business 72, 183-200.

Daniel, K., D. Hirshleifer and A. Subrahmanyam. (1998). "Investor Psychology and Security Market Under- and Over-reactions." Journal of Finance 3, 1839-1886.

Daniel, K., D. Hirshleifer and A. Subrahmanyam. (2001). "Overconfidence, Arbitrage, and Equilibrium Asset Pricing." Journal of Finance 61, 921-965.

Fama, E. F. and K. R. French. (1993). "Common Risk Factors in the Returns on Stocks and Bonds." Journal of Financial Economics 33, 3-55.

Fama, E. F. and K. R. French. (1995). "Size and Book-to-Market Factors in Earnings and Returns." Journal of Finance 50, 131-155.

Gould, J. B. and E. H. Sorensen. (1986). "A Factor in Equity Pricing." Journal of Portfolio Management $13,38-43$.

Ibbotson Associates. (1999). Stock, Bonds, Bills and Inflation 1999 Yearbook. Chicago, IL: Ibbotson Associates.

Lakonishok, J., A. Shleifer and R. Vishny. (1994). "Contrarian Investment, Extrapolation and Risk." Journal of Finance 49, 1541-1578.

Lanstein, R. and W. Sharpe. (1978). "Duration and Security Risk." Journal of Financial and Quantitative Analysis 13, 653-668.

Leibowitz, M. (1986). "Total Portfolio Duration: A New Perspective on Asset Allocation." Financial Analysts Journal 42:5, 18-29, 77.

Leibowitz, M. and S. Kogelman. (1993). "Resolving the Equity Duration Paradox." Financial Analysts Journal 49:1, 51-65.

Macaulay, F. R. (1938). Some Theoretical Problems Suggested by the Movements of Interest Rates, Bond Yields, and Stock Prices in the United States since 1856. New York: National Bureau of Economic Research.

Nissim, D. and S. H. Penman. (2001). "Ratio Analysis and Equity Valuation: From Research to Practice." Review of Accounting Studies 6, 109-154.

Penman, S. H. (1991). "An Evaluation of Accounting Rate-of-Return." Journal of Accounting, Auditing and Finance 6, 233-256.

Stigler, G. J. (1963). Capital and Rates of Return in Manufacturing Industries. Princeton, NJ: Princeton University Press. 